\title{
Em busca de um ponto cego: notas sobre a sociologia da cultura no Brasil e a diluição da mídia como objeto sociológico
}

Recebido: 15/12/2010 Aprovado: 13/07/2011

1. Professora do Departamento de Ciências Sociais e do Programa de Pós-Graduação em Sociologia da UFPE. E-mail:

me.rocha@uol. com.br

Resumo: Este texto discute as possíveis causas e consequências do fraco estatuto da mídia como objeto na área acadêmica da sociologia. Para tanto, analisa certas tendências recentes do campo cultural brasileiro que apontam para um desgaste do cânone modernista diante da emergência de gerações de artistas, intelectuais e públicos que sofrem influência decisiva da indústria cultural.

Palavras-chave: Sociologia da comunicação, sociologia da cultura, modernismo, pós-modernismo, Indústria cultural

xiste uma sociologia da comunicação no Brasil? Se considerarmos a proeminência dos estudos sobre intelectuais na sociologia da cultura brasileira, evidenciada em recente balanço de Maria Arminda do Nascimento Arruda sobre o tema (2010), seremos levados a concluir que o estatuto da mídia como objeto é muito fraco na área acadêmica da sociologia. Este artigo pretende discutir os custos dessa lacuna e apontar algumas de suas possíveis razões.

Na verdade, é preciso levar em conta que a própria sociologia da cultura é um campo tardio e pouco desenvolvido das ciências sociais, caracterizado pelo agrupamento de estudos sobre arte, produção intelectual e meios de comunicação (WILLIAMS, 1992) com graus muito diferenciados de reconhecimento no campo acadêmico. Nos países centrais, o recorte da cultura como objeto sociológico específico foi correlato ao avanço da autonomização da esfera da arte erudita, que se tornou, de saída, o cânone de avaliação e interpretação das demais formas de manifestação cultural, no século XX (ORTIZ, 2002, p. 3). 
No Brasil, o primeiro impacto da autonomização relativa da esfera da cultura erudita se fez notar no próprio surgimento do que se convencionou chamar de "pensamento social brasileiro". Assim, em um primeiro momento, ela trouxe, não a transformação da cultura em objeto privilegiado de um nascente pensamento social, mas, sim, a constituição de um campo cultural no qual esse mesmo pensamento passou a existir, sob a égide de um cânone modernista. Maria Arminda do Nascimento Arruda assinala esse fato e aponta a linha de continuidade que existe entre os intérpretes do Brasil, desde a década de 1930, e uma sociologia dos intelectuais que constitui hoje a fração mais consagrada da sociologia da cultura brasileira. Apoiada na análise de Antônio Candido sobre aqueles intérpretes, ela explica:

(...) a formação do pensamento brasileiro acaba por coincidir com a
constituição de uma intelectualidade de corte modernista, identifi-
cada com as questões do país e dedicada à construção da socieda-
de moderna neste lado do mundo. A temática da formação refere-
se, em suma, à própria consolidação do campo intelectual no Brasil.
Daí, a identificação dos ensaístas dos anos de 1930 como "intérpre-
tes do Brasil", em claro obscurecimento dos intelectuais preceden-
tes, elucida-se quando os inserimos na tradição modernista, assu-
mida como expressão mais genuína da nossa cultura, introdutora
de verdadeira ruptura do tecido cultural, representante dos câno-
nes mais avançados nos centros hegemônicos. (ARRUDA, 2004, p. 6)

Interessante é perceber, como faz Arruda, que o próprio Antônio Candido se inscreve na tradição que analisa, mas a um passo adiante na direção de tomar a cultura como objeto particular de análise, entendendo-a como produção intelectual e literária. Desse modo, a influência de um cânone modernista de cultura continua a incidir nas gerações posteriores, a começar pelo tipo de produção cultural que é tomada como objeto preferencial, a literatura. Tanto mais porque Antônio Candido foi migrando para a crítica literária e se afastando da sociologia, do ponto de vista acadêmico, a ponto de abrir caminho para uma tradição que inclui nomes como Roberto Schwarz e Rodrigo Naves. Embora de forte inspiração sociológica, de matiz adorniana, a sua obra não delineou institucionalmente um campo da sociologia da cultura brasileira, ainda que tenha influência sobre os que se situam nesse campo. A longa trajetória, que vai do pensamento social brasileiro até a tradição de crítica da cultura, personificada em Antonio Candido, tem uma força simbólica e institucional que ajuda a entender o surgimento tardio de uma sociologia da comunicação ou da "cultura de massas" no Brasil.

Renato Ortiz menciona como pioneiro um artigo de Ferreira Gullar, de 1966, versando, especificamente, sobre os problemas estéticos da 
"sociedade de massas", a partir da perspectiva frankfurtiana. Na mesma direção, ele registra também a organização, por Vamireh Chacon, de um número da revista Tempo Brasileiro dedicado à comunicação e à cultura de massas. Mas, até a década de 60, segundo Ortiz, a temática da "cultura de massas" era ofuscada por aquelas da cultura popular e da identidade nacional (ORTIZ, 1988, p. 15), temas que deitam raízes já na primeira geração de modernistas e que continuaram sendo revisitados desde então. O problema da formação nacional, desse modo, se desdobrava na busca por uma identidade brasileira mais facilmente localizável nas culturas erudita e popular. Mas isso significava deixar de lado o fato de que a indústria cultural começava a remodelar profundamente o contexto no qual ambos os tipos de produção cultural passaram a existir.

Somente a partir da década de 1970 , surgiu na USP um conjunto de estudos que tentavam dar conta das transformações trazidas pela consolidação de uma indústria cultural no país². A tese de doutoramento de Gabriel Cohn, que inspirou esses estudos, enunciava como objetivo central "a fundamentação de uma estratégia de análise sociológica das relações entre sistemas simbólicos e sistemas sociais, aplicável a uma modalidade historicamente específica da sua manifestação: qual seja, a sociedade contemporânea altamente complexa e industrializada, em que a produção e o consumo em grande escala se estendem até a sua dimensão cultural" (COHN, 1973, p. 13). Nesse texto capital para a sociologia da comunicação no Brasil, o autor propõe como objeto a relação entre sistemas simbólicos e sistemas sociais no quadro do capitalismo monopolista e sua manifestação no âmbito da cultura, a indústria cultural, força-motriz da concentração técnica e econômica, que passa a caracterizar a vertente mais caudalosa da produção de bens simbólicos e redefinir o estatuto das demais.

O conceito de "indústria cultural" foi a base para a pesquisa dos processos de racionalização que, na década de 1970, atingiam os diferentes ramos da produção simbólica, tais como a publicidade, o jornalismo e a música. Uma safra de estudos da comunicação inspirados na Teoria Crítica seguiu-se à introdução dessa corrente por Gabriel Cohn, na USP dos anos 70. Nesse período, ele orientou alguns dos principais trabalhos dessa fornada inicial, tais como as dissertações de mestrado de Maria Arminda do Nascimento Arruda, Gisela Taschner, Waldenyr Caldas, Ciro Marcondes Filho e Orlando Pinto Miranda (ARRUDA, 1979; TASCHNER, 1978; CALDAS, 1976; MARCONDES FILHO, 1976 e MIRANDA, $1975)^{3}$. Mas, a partir da década de 80, esses expoentes foram migrando para outros temas e, eventualmente, também para outras perspectivas teóricas.

Maria Arminda do Nascimento Arruda voltou-se para os problemas da alta cultura e, já em seu doutorado, elegeu como tema "o imaginário mineiro na vida política e cultural no Brasil", tratado a partir das obras de intelectuais de Minas. Mais recentemente, tem dedicado especial atenção ao projeto cultural
2. É conhecida a iniciativa anterior de Luiz Costa Lima para a divulgação, no Brasil, de teóricos que abordaram a comunicação, inclusive Adorno e Horkheimer. Mas ele próprio reconheceu o caráter quase acidental desse objeto em sua trajetória, em contraste com a produção uspiana sobre o tema, bem mais ampla e longeva.

LIMA, Luiz Costa. Teoria da cultura de massa. 2a. ed. (1’a ed. 1970) São Paulo: Paz e Terra, 1978, p. 11.

3. De certo modo, A moderna tradição brasileira, de Renato Ortiz, se inscreve na mesma tradição ao se apoiar nas pesquisas desses autores para analisar a constituição de uma indústria cultural brasileira como um todo. De certo modo, A moderna tradição brasileira, de Renato Ortiz, se inscreve na mesma tradição ao se apoiar nas pesquisas desses autores para analisar a constituição de uma indústria cultural brasileira como um todo. 
modernista, o que transparece inclusive em sua tese de livre-docência "Metrópole e Cultura: São Paulo no Meio Século". É muito importante frisar que Adorno permanece como uma referência fundamental, tanto em suas preocupações com o modernismo, quanto quando trata de políticas culturais e sociologia da cultura. Mas a indústria cultural nunca mais foi objeto de suas investigações.

Depois da dissertação de mestrado orientada por Gabriel Cohn e defendida em 1979, Gisela Taschner deu prosseguimento à pesquisa sobre a constituição da indústria cultural no segmento da mídia impressa em seu doutorado sobre o grupo Folha de São Paulo, apresentado em 1984, sob a orientação de Azis Simão. Mas, desde então, tem privilegiado os temas do consumo, do turismo e do lazer a partir de outras perspectivas, como a de Norbert Elias, central em seu artigo "Raízes da Cultura do Consumo" (1997). Pioneira na sociologia do consumo brasileira, Gisela Taschner dedicou boa parte de seus esforços posteriores ao doutorado à pesquisa sobre a estruturação do mercado de lazer e turismo, a difusão da cultura de consumo e a expansão dos direitos do consumidor no Brasil.

A produção de Ciro Marcondes Filho também parece associar, à mudança de tema, uma abordagem mais eclética em que a perspectiva frankfurtiana não parece ter a primazia. Francisco Rüdiger, analisando esse movimento, chega ao ponto de afirmar que, na produção do autor, "a problemática não se situa mais na esfera da indústria cultural, deslocando-se para o âmbito do discurso pósmoderno sobre a técnica" (1998, p. 20). Entretanto, o legado frankfurtiano ainda está presente na análise que o autor faz das transformações trazidas com a era digital. Em texto de 2001, onde traça uma interpretação mais geral do fenômeno da internet, Marcondes Filho expressa preocupações que ressoam aquele legado, como, por exemplo, quando aponta o controle do processo de digitalização da cultura por grandes empresas privadas como uma das suas principais ameaças. Essa influência é ainda mais presente quando ele recorre à teoria marxiana do valor para explicar a era digital como um novo estado do processo de abstração posto pela expansão do trabalho abstrato. Mas, nesse mesmo texto, Ciro Marcondes Filho insiste na especificidade da internet, o que dificilmente lhe permitiria ser englobada pelo conceito de indústria cultural: "Ao que tudo indica, a internet não pertence ao campo da comunicação nem se submete à lógica dos meios de comunicação: ela é outra coisa. É, sem dúvida, o primeiro grande sistema estruturante da sociedade tecnológica. Os meios de comunicação ainda pertencem ao quadro anterior da modernidade e do humanismo: ainda remetem, no plano do inconsciente, a questões como esfera pública, representação, veiculação ideológica, manipulação, poder, etc. São sistemas coerentes com aquele quadro histórico e social. A internet materializa a lógica da nova sociedade que se constitui a partir da virada do século; já não é mais comunicação, estamos na era do delírio técnico travestido de comunicação" (2001, p. 40). 
Aqui interessa destacar que o uso das novas tecnologias e de seu potencial mais fragmentário e descentralizador para invalidar o conceito de indústria cultural é um dos fatores que contribuíram para a diluição da mídia como objeto nas ciências sociais, uma vez que a relação entre os sistemas sociais e os sistemas simbólicos que estava pressuposta naquele conceito não precisa aparecer com a mesma força no tratamento das novas tecnologias. Isso não passou despercebido por Gabriel Cohn e foi alvo de duas intervenções suas no sentido de reafirmar a atualidade daquele conceito. A primeira delas faz, inclusive, referência aos trabalhos como os do Centro de Pesquisa em Novas Tecnologias, Comunicação e Cultura, então coordenado por Ciro Marcondes Filho, na ECA/USP. Trata-se do texto "Esclarecimento e ofuscação: Adorno e Horkheimer hoje", em que Cohn, considerando as possibilidades postas pelas novas tecnologias, conclui que "em nenhum desses casos haverá condições para demonstrar que os grandes conglomerados empresariais estejam hoje significativamente mais sob o controle de uma cidadania formada por sujeitos autônomos de uma razão reflexiva do que era o caso quando foi escrita a Dialética do Esclarecimento" (1998, p. 23). A outra tentativa de Gabriel Cohn intitula-se justamente "a atualidade do conceito de indústria cultural”, em que apresenta argumentos na mesma direção (1998).

Entretanto, essas intervenções, que reforçam a atualidade da Teoria Crítica e, mais especificamente, do conceito de indústria cultural, situam-se fora do campo de estudos de comunicação que, a partir dos anos 70, foi ganhando forma e dinâmica próprias. Além disso, foram iniciativas excepcionais em relação ao conjunto da produção de Cohn desde então, mais voltada à teoria sociológica geral. Depois de sua tese sobre a sociologia da comunicação, elegeu Max Weber como tema de sua livre-docência, já em 1977 (1979). É certo que, na década de 1980, escreveu textos importantíssimos sobre políticas culturais no Brasil (1987, 1984). Mais recentemente, tem dedicado artigos a Simmel, Luhmann, Tocqueville e ao próprio Weber (2000, 2003). Ainda assim, a Teoria Crítica, e Adorno em especial, continuam centrais para Gabriel Cohn. Além dos dois artigos já mencionados em que reafirma a atualidade da perspectiva frankfurtiana, Cohn publicou também "Difícil reconciliação: Adorno e dialética de cultura" (1990).

A mudança de interesses vista na trajetória dos autores pioneiros da sociologia da comunicação de matiz frankfurtiana parece corresponder a um movimento da sociologia brasileira como um todo, que não tem priorizado esse objeto, haja vista a fraca presença do tema nas reuniões anuais da ANPOCS. Analisando a programação dos grupos de trabalho e seminários temáticos, nos últimos treze anos, vê-se que a principal discussão sobre a mídia tem sido aquela que trata especificamente de sua influência no comportamento eleitoral e na opinião pública, presente em todos os anos do encontro, desde pelo menos 1998, sob a perspectiva da ciência política ${ }^{4}$.
4. Dados disponíveis no site da ANPOCS, em junho de 2011. A programação dos seminários dos encontros de 2008 e 2009 não pode ser acessada. A primeira, por suposta falha no endereço eletrônico. A segunda não constava entre as opções do menu. 
5. Dados disponíveis no site da CAPES, em junho de 2011.
O tema da "mídia, consumo e relações de poder" apareceu duas vezes no mesmo período, enquanto a preocupação com as influências das novas tecnologias de informação em diferentes áreas da vida social se expressou em mais quatro seminários temáticos. O grupo onde o tratamento sociológico da mídia mais tinha espaço tratava de um tema mais geral: a economia e a política do simbólico. Será que a centralidade da mídia nas sociedades contemporâneas, atestada, por exemplo, na sua crescente importância para a representação de processos políticos, de experiências religiosas e de identidades sociais, vai diluí-la como objeto e transformá-la em um ponto cego da investigação sociológica no Brasil? A esse respeito, é importante lembrar que o tratamento analítico da mídia como parte de processos sociais específicos não substitui uma discussão sistemática sobre sua relação com a cultura, nas sociedades contemporâneas, o que seria o objeto próprio de uma sociologia da comunicação.

Ao mesmo tempo em que se consolidava um campo de pesquisas em comunicação, houve um refluxo do tema na sociologia da cultura brasileira, e a sua transformação em um dos fatores explicativos de processos sociais os mais variados. Tratando do primeiro ponto, é sabido que aquele campo ganhou novo estatuto com o surgimento da Intercom - Sociedade Brasileira de Estudos Interdisciplinares em Comunicação - em 1977. De acordo com Anamaria Fadul, isso se deveu em parte à conjuntura internacional, especialmente ao debate sobre a Nova Ordem Mundial da Informação e da Comunicação, realizado na ONU, nos anos 70, mas que só se implantou definitivamente no Brasil a partir do início dos anos 80 , quando a redemocratização diminuiu a resistência de pesquisadores reticentes em participar de um debate até então conduzido por um governo autoritário (2003, p. 264). Mas, certamente, para além desse fator conjuntural, foi a própria consolidação de uma indústria cultural que ampliou a necessidade de um conhecimento especializado como parte da racionalização da produção simbólica. Desde então, o espaço acadêmico da comunicação cresceu muito, dando origem a outras sociedades científicas, como a COMPÓs, em 1992 e a Socine, em 2000. Já no século XXI, espanta a velocidade da expansão dos programas de pós-graduação em comunicação, que eram 15 reconhecidos pela Capes em 2003 e hoje somam $55^{5}$.

Quanto ao refluxo do tema na sociologia da cultura, além da trajetória dos pioneiros aqui assinaladas, cabe destacar, também, o papel de Sérgio Miceli como referência primeira para uma crescente e consagrada sociologia dos intelectuais, desde o seu trabalho "Intelectuais e classe dirigente no Brasil", de 1979. Nessa vertente, reatualiza-se a linhagem do pensamento social brasileiro, de corte modernista. Maria Arminda do Nascimento Arruda assinala esse fato e sugere para ele uma explicação muito interessante: 
(...) é possível aproximar a sociologia dos intelectuais - ramo da sociologia da cultura - do pensamento brasileiro, tendo em vista que o objeto da reflexão obriga o retorno das preocupações com os mesmos problemas, desvelando orientações valorativas comuns. $\mathrm{O}$ tratamento das tensões e dos impasses subjacentes à constituição da sociedade moderna no Brasil passa a realizar-se por meio da avaliação das elaborações intelectuais, dos dilemas vividos por seus praticantes no esforço de construção de uma experiência culturalmente relevante num meio atravessado por concepções acanhadas e caracterizado por oportunidades limitadas. A profusão de estudos sobre os intelectuais no Brasil talvez resulte da sensação de perda progressiva das antigas posições desfrutadas por uma intelligentsia que se formou desenhando retratos do país, elaborando diagnósticos, concebendo projetos, vislumbrando trajetórias futuras. O tratamento dos limites de atuação dos intelectuais enleia-se na percepção das hesitações da nossa modernidade, sintoma do desconforto diante do presente, móvel do impulso para nomear essas realizações arrevesadas. (2004, p. 10)

Gostaria, aqui, de assinalar dois pontos. Por um lado, para além do elo de continuidade que liga a sociologia dos intelectuais contemporânea à tradição modernista, expressa no pensamento social brasileiro, a perspectiva bourdiesiana utilizada por Miceli produz uma revisão crítica daquela tradição, porque problematiza as obras daqueles intelectuais a partir de suas condições de produção, manifestas nas diferentes trajetórias profissionais de cada um deles. $O$ resultado é uma relação nada reverencial com a tradição. Por outro lado, ao eleger esse tipo de produção como o centro de uma sociologia da cultura brasileira, acaba por reatualizar o cânone modernista em um contexto claramente pós-moderno, em que a lógica da mercadoria alcança praticamente todos as formas de produção cultural. E aqui a interpretação lançada por Arruda merece muito ser explorada: a proeminência de uma sociologia dos intelectuais no Brasil é também sintoma de uma mudança no próprio estatuto dos intelectuais de inspiração modernista na sociedade brasileira (2010). Na base dessa mudança, está, em primeiro lugar, o enfraquecimento do cânone modernista de cultura diante da consolidação de uma indústria cultural - o que, para Jameson, constitui o pósmodernismo como a lógica cultural do capitalismo tardio (1996). Em segundo lugar, está também a transformação das condições do trabalho intelectual no Brasil pela institucionalização da pós-graduação, a partir da década de 1960, e a racionalização das práticas de pesquisa e ensino. Tanto a implantação de uma indústria cultural quanto essas mudanças no âmbito acadêmico são consequência da modernização empreendida desde o Regime Militar instaurado em 1964. 
A expansão e consolidação de um sistema universitário, sobretudo em nível de pós-graduação, além de profissionalizarem o trabalho intelectual de modo definitivo, foram corroendo o seu caráter artesanal, pelo aumento dos constrangimentos que passaram a pesar sobre os professores, premidos entre demandas crescentes como a produção bibliográfica, a orientação de trabalhos, a participação em bancas de defesas de teses e dissertações, etc. Ao mesmo tempo, a racionalização da produção intelectual foi ditando o surgimento das diferentes especialidades na sociologia, dentre as quais, a sociologia da cultura, da qual aquela sociologia da comunicação uspiana constituiu um momento importante. Mais recentemente, chegamos a um ponto de extrema fragmentação da cultura como objeto, ditada pela especialização crescente dos profissionais e pela subdivisão dos campos acadêmicos, a começar pela separação entre a sociologia e a comunicação, até chegar às divisões internas em cada um desses espaços institucionais.

Na comunicação, por exemplo, parece haver, hoje, uma divisão do trabalho entre os que analisam as condições institucionais e econômicas da produção simbólica e os que se detém sobre os produtos e mensagens propriamente ditos. Os primeiros se agrupam na linha que se convencionou chamar de "economia política da comunicação" e, pelo menos até recentemente, pareciam entrincheirados diante de uma leitura pouco politizada dos estudos culturais, muito popular no campo, a partir da recepção da obra de Jesus Martin-Barbero. Desempenham, assim, um papel fundamental de politização do debate, mas, talvez até por isso mesmo, ocupam um lugar marginal no campo da comunicação. Outros orbitam os estudos de linguagem e estética e eventualmente convocam aspectos extradiegéticos nas suas análises. Em ambos os casos, podem fazer uso da sociologia, mas isso não deveria eximir a nossa área de uma reflexão mais sistemática sobre a mídia. O mesmo vale para o esforço interdisciplinar de reflexão sobre a cultura articulado em torno da Redecult, a partir da Universidade Federal da Bahia.

Enquanto isso, os estudos sobre a produção intelectual aparecem como a fração mais consagrada de uma sociologia da cultura brasileira e, ainda que não adotem uma perspectiva pós-moderna (muito pelo contrário), participam da pulverização temática que o pós-modernismo produz no âmbito acadêmico, uma vez que não têm como foco principal uma análise mais ampla sobre as condições estruturais que tem resultado, inclusive, na redefinição do estatuto do trabalho intelectual no Brasil. Isso porque tal análise precisaria tratar, também, da indústria cultural como força decisiva no campo da produção simbólica, que provocou a perda de importância relativa do cânone modernista na cultura brasileira, cânone este expresso na produção intelectual que é objeto de análise preferencial. Assim, o grande espaço que os trabalhos sobre intelectuais têm tido pode refletir a necessidade de reinterpretação do sentido do próprio 
trabalho intelectual no novo contexto, em que tanto as rotinas de produção mais racionalizadas quanto a difusão em grande escala de produtos culturais industrializados parecem ameaçar o seu lugar tradicional.

No novo cenário, a indústria cultural desponta como a antagonista tanto dos agentes alinhados ao cânone modernista, quanto daqueles que se opõem a esse cânone, sobretudo no âmbito das políticas públicas. Ela é o inimigo comum cuja presença se tornou inevitável. Do ponto de vista da esfera de produção erudita, como é sabido, a emergência do pós-modernismo implica a diluição de limites entre a "alta cultura" e a "cultura de massas", uma vez que os formatos e linguagens desenvolvidos no âmbito desta ultima são incorporados e ressignificados naquela esfera, indicando o momento em que antigos enclaves modernistas passam a ser permeados pela presença da indústria cultural (JAMESON, 1996).

No Brasil, é possível apontar alguns indícios que sugerem uma mudança na mesma direção. O mais importante é o surgimento de uma geração de produtores culturais já socializados pela TV, pelo cinema hollywoodiano, pelo rock, pela cultura pop de uma maneira geral. Marcelo Ridenti identificou esse transcurso geracional como o declínio de uma "estrutura de sentimentos de brasilidade revolucionária" que marcava a geração anterior e a emergência de uma outra ainda carente de definição (2005).

Enquanto as gerações modernistas de meados do século XX compreendiam a cultura como um instrumento de transformação social e de construção nacional, tomando, para tanto, a cultura popular e o mundo rural como referências primeiras, via de regra, as novas gerações de produtores culturais já têm, nas linguagens e formatos da indústria cultural, um parâmetro incontornável. Analisei essa transformação a partir da biografia muito particular de um desses produtores, o diretor de TV e de cinema Guel Arraes, cujo núcleo, no interior da Rede Globo, atuou como um espaço de troca entre a emissora, carente de legitimidade diante da pressão da opinião pública e do aumento da concorrência, e uma geração de artistas vindos do vídeo independente, do jornalismo "nanico" e do teatro cômico dos anos 1980 (ROCHA, 2008). Se a "estrutura de sentimentos" é a partilha de crenças e sensibilidades que atuam como mediação entre a experiência histórica comum e a produção artística e intelectual, a dessa nova geração emerge da desconfiança em relação à apropriação autoritária do nacional-popular pelo Regime Militar, da recusa de uma compreensão estritamente classista da política, da influência de uma concepção mais psicanalítica e contracultural de liberdade. Mas, no caso dos artistas agrupados em torno de Guel Arraes, ela recupera dois elementos importantes do modernismo, pelo menos em suas pretensões: a busca pela inovação de linguagem e pela representação dos segmentos oprimidos da sociedade. Esses elementos, especialmente o primeiro, são a base para a reivindicação de uma legitimidade cultural que extrapola o âmbito da TV e, 
6. Em entrevista disponível no site www.heloisabuarquedeholanda. com.br, consultado em 02 de junho de 2011.

7. Gil (2003) disponível em: http://www. cultura.gov.br/site/ categoria/o-dia-adia-da-cultura/discursos/ pelo menos no campo do cinema, se contrapõe explicitamente ao cânone "cinema-novista".

A questão fundamental é saber até que ponto se trata de um veio que, por estar amparado na indústria cultural, alcança grande visibilidade, mas pouca consagração na esfera de produção erudita ou se, a partir dessa visibilidade, consegue ampliar os critérios de legitimidade cultural em todos os âmbitos. Ao contrário do que possa parecer, a resposta não é simples. No caso dos produtores que investiguei, um dos seus temas preferenciais, a periferia, acabou virando objeto de uma grande exposição realizada no Rio de Janeiro, em 2005. Uma de suas idealizadoras, a pesquisadora Heloísa Buarque de Holanda, a definiu como "uma exposição sobre a visualidade e a linguagem cultural da periferia do Rio de Janeiro, retratando sua maneira de captar o mundo da mídia e da moda de forma antropofágica, transformadora e criativa, dentro de sua realidade econômica" ${ }^{\prime}$. Indo além, ela afirma: "é inquestionável a importância dessas expressões culturais no conjunto da diversidade que nos caracteriza. Não podemos definir identidade cultural nacional, simplesmente porque ela não existe no singular. Nossa cultura é plural e as estéticas centrais e periféricas, como o tecnobrega de Belém, o funk carioca ou o hip hop paulistano, compõem essa multiplicidade, sendo cada vez mais reconhecidas, também por isso".

A referência à antropofagia e à identidade nacional, agora, no plural, indica que, mais do que a renúncia à antiga forma de consagração, temos aqui o aumento da disputa em torno do poder de definir os critérios de legitimidade cultural, e o fato de que a visibilidade midiática passa a contar como um recurso importante nessa disputa - como, de resto, tem contado nas disputas do campo político, religioso, etc. Além disso, esse caso sugere também a projeção dessa disputa no âmbito acadêmico, uma vez que a contestação ao cânone modernista empreendida por produtores culturais dentro e fora da indústria cultural recebe a chancela de pesquisadores, como a própria Heloísa Buarque de Holanda e Hermano Vianna, interlocutor frequente de Regina Casé e Guel Arraes e um claro defensor de uma releitura do valor cultural do funk carioca.

Tampouco no âmbito das políticas públicas, o contexto é favorável ao cânone modernista. Em seu lugar, tem ganhado força uma concepção mais antropológica de cultura que amplia o leque das manifestações culturais dignas de apoio por parte do Estado. Desde o seu discurso de posse, em 2003, o então ministro da cultura Gilberto Gil deixou clara a nova concepção que deveria nortear a atuação do Estado: "cultura" deveria contemplar a produção constante de significados, hábitos, valores e identidades que surgem a partir das interações sociais ${ }^{7}$. Tal concepção acabou reverberando no Plano Nacional de Cultura, que diz: 
A Cultura não se resume tão-somente ao campo das belas-artes, da filosofia e da erudição, nem tampouco ao mundo dos eventos e efemérides. A Cultura deve ser considerada como o conjunto dos traços distintivos que caracterizam um determinado grupo social. Além das artes, da literatura, contempla, também, os modos de vida, os direitos fundamentais do homem, os sistemas de valores e símbolos, as tradições, as crenças e o imaginário popular. (MINISTÉRIO DA CULTURA, 2009, p. 5)

O reconhecimento da legitimidade dos modos de vida como experiência cultural remete não apenas à velha celebração da cultura popular, presente nas políticas de governos anteriores, mas também a práticas culturais que, apesar de não serem sustentadas pelo mercado, guardam afinidade com formatos e linguagens da indústria cultural. A criação de uma Secretaria do Audiovisual, por exemplo, é indicativa desse fato. Não se trata de uma "secretaria do cinema", mas do audiovisual, muito próxima à produção da periferia carioca, a partir da experiência do Festival "Visões Periféricas". Além disso, mesmo as manifestações populares não estão isentas da lógica do espetáculo, que parece ter extravasado a mídia e alcançado outras formas de produção cultural. A incorporação daquelas manifestações pela indústria do turismo e nas grandes festas financiadas pelo Estado não está isenta daquela lógica. Soube de um caso em que a um grupo de pastoril foi encomendada uma reformulação nos moldes de um pocket show, para a apresentação no carnaval.

Apesar de se contrapor ao mercado como mecanismo exclusivo de sustentação da cultura, a recuperação do poder do Estado nessa esfera se dá em um contexto no qual a presença da indústria cultural é decisiva e pode aparecer para os gestores como um obstáculo à experimentação de formas que não ecoem os gostos predominantes. Recentemente, um conflito entre o governo do Estado da Paraíba e a Prefeitura de Campina Grande a respeito da organização da festa de São João naquela cidade expôs esse fato com muita clareza. O governo do Estado recusou-se a financiar o São João de Campina Grande e deu como justificativa o fato de que não cabia ao poder público investir na contratação de atrações com grande visibilidade midiática, enquanto os artistas locais permaneciam à margem da festa. Do ponto de vista da Prefeitura, essas atrações são importantes para garantir o fluxo turístico que aumenta a arrecadação fiscal e os dividendos políticos perante a população da cidade. Isso significa que, mesmo gestores culturais preocupados em ampliar o espaço para a produção e consumo de bens simbólicos alternativos em relação à indústria cultural têm que se haver com a sua força na disseminação de gostos e hábitos. Além disso, não podem ficar indiferentes à visibilidade midiática de artistas, seja na concessão de incentivos fiscais, seja na consagração propriamente cultural. 
8. Matéria de 19 de dezembro de 2003, disponível no site do Ministério da Cultura, acessado em 02 de junho de 2011.
Em junho de 2009, um embate entre Caetano Veloso e o Ministério da Cultura terminou com a autorização do uso da Lei Rouanet para financiar o show do cantor. Em princípio, essa autorização havia sido recusada a pretexto de ser ele um artista comercialmente viável. O então ministro Juca Ferreira voltou atrás e lembrou que a Lei Rouanet não prevê esse tipo de restrição e que até Ivete Sangalo já havia sido beneficiada (Folha de São Paulo. Ilustrada, 23/06/2009). No tocante à consagração, em 2003, o presidente Lula e o ministro Gilberto Gil concederam o prêmio da Ordem do Mérito Cultural a um grande número de artistas e intelectuais. A lista incluía desde Cândido Portinari e Pixinguinha, até os membros do Casseta e Planeta, além da dupla Zezé de Camargo e Luciano ${ }^{8}$.

No campo acadêmico das ciências sociais, as diferenças entre as concepções modernista e antropológica de cultura parecem estar projetadas nas obras de Sérgio Miceli e Renato Ortiz, como duas das maiores influências da sociologia da cultura brasileira. De um lado, a ênfase recai sobre a produção erudita de corte nacional. De outro lado, recebe maior atenção a produção "popular de massa" e a problemática é situada no âmbito da mundialização. Em comum, a forte influência bourdieusiana sobre ambos os autores, embora Renato Ortiz tenha sido levado a um diálogo maior com os estudos culturais, até pelo tipo de produção de que se ocupou. Isso porque a perspectiva de Bourdieu, muito operacional para lidar com a constituição e as mudanças no subcampos específicos da cultura, pode sofrer de um deslocamento temporal e espacial para lidar com a dinâmica do campo cultural no Brasil de hoje. Senão vejamos: nas análises daquele autor, a cultura erudita é a referência primeira para o julgamento de todos os bens simbólicos, cabendo à indústria cultural simplesmente vulgarizar o consumo dos bens consagrados e, no mesmo movimento, retirar-lhe a legitimidade cultural de que dispunham como bens raros. A esse respeito, ele diz:

Verifica-se que o sistema da indústria cultural tende a realizar em
bases explicitas as operações segundo as quais sempre se elaborou
o que se denomina de arte popular (sistema de bens culturais con-
sumidos pelas classes populares nas sociedades estratificadas do oci-
dente europeu) e que não passa, no essencial, de uma arteerudita
de uma época anterior, sistematicamente reinterpretada em função
de um tipo determinado de uso social. (BOURDIEU, 1982, p. 142).

Apesar de matizar essa posição no mesmo texto, reconhecendo que a cultura popular é mais próxima da "arte média" produzida pela indústria cultural, pelo critério da maior acessibilidade, Bourdieu reafirma que aquela arte é um substituto degradado e desclassificado da cultura legítima (1982, p. 142). No Brasil, Sérgio Miceli mostrou o papel decisivo dos meios de comunicação na unificação do mercado de bens simbólicos e na disseminação de um arbitrário cultural dominante, uma vez que, historicamente, ocuparam um vácuo 
deixado pela ausência de um sistema de ensino universal e de qualidade, a quem caberia disseminar o reconhecimento daquele arbitrário entre as classes mais baixas $(1982 ; 1984)$.

No momento de consolidação de uma indústria cultural brasileira, o déficit de escolarização de uma grande parcela da população impedia um maior aproveitamento da produção erudita pelo projeto de imposição "pedagógica" da cultura dominante (MICELI, 1982, p. 184). Esse projeto encontrou, na indústria cultural, um suporte muito mais adequado, na medida em que pode atuar em larga escala, já que, para tanto, não demanda uma generalização do acesso à escola de qualidade. Nas palavras de Miceli: "os meios de comunicação de massa constituem, no interior de uma formação social como a brasileira, cujo mercado material e simbólico não se encontra unificado, os instrumentos estratégicos a serviço de uma segunda ação pedagógica que consiste em ressocializar amplos contingentes pela imposição de um habitus de classe 'dominante'" (1982, p. 213). Tratando de um contexto particular, mostrei como a publicidade atuou no sentido de representar esse habitus de classe sobretudo em termos de padrões de consumo, conformando uma situação em que a superioridade das classes dominantes, mesmo do ponto de vista simbólico, tende a se expressar mais em termos de acesso a bens e serviços mais caros do que na demonstração de um gosto erudito, para muitos sequer reconhecível como tal (ROCHA, 2002).

Além das mediações necessárias ditadas pela sociedade brasileira, a perspectiva bourdieusiana precisa também ser ajustada do ponto de vista da sua temporalidade. Se Miceli nos alerta para os limites de influência do cânone da cultura erudita em um cenário de fraca escolarização, é preciso considerar também que, mesmo quando restringimos o olhar para a dinâmica interna àquela esfera, o cânone modernista não parece ter a mesma força do que no começo ou em meados do século XX. A razão principal, como tentei apontar, é a ascensão do pós-modernismo como a lógica cultural do capitalismo tardio. Talvez isso explique, em parte, a popularidade dos estudos culturais no campo da comunicação, alimentada pela tendência de consagração das culturas populares e de fusão da alta cultura com a cultura de massa, nesse contexto.

Jesus Martin-Barbero, um dos autores mais celebrados naquele campo, sugere que o massivo se constituiu a partir da releitura de gêneros da cultura popular, em vez de ser a diluição de linguagens e obras da cultura erudita, sobretudo na sociedades latino-americanas (2001). Não se trata da afirmação genérica acerca de uma relação orgânica entre indústria cultural e culturas populares, pois a análise dessa relação é matizada pelos processos políticos e econômicos de constituição dos Estados Nacionais e de consolidação da etapa avançada do capitalismo na América 
Latina. Ainda assim, Barbero oferece outra via para pensar o papel da indústria cultural em uma sociedade de classes, em que sua força ideológica consiste justamente na oferta de narrativas em que as classes populares possam se reconhecer e se sentir incluídas, e não tanto na disseminação de um arbitrário cultural dominante. Também é possível antever, nessa concepção, as possibilidades de uma leitura populista dos estudos culturais.

No cruzamento dessas influências, caminha a sociologia da cultura brasileira, desde os já citados estudos sobre intelectuais, passando pelas análises dos diferentes campos de produção cultural em vias de autonomização, como a moda, a dança e o cinema, até os estudos sobre políticas culturais e sobre as culturas populares na sua interface com o Estado e com o mercado. No contexto do pósmodernismo, a mídia perpassa cada uma dessas áreas, como tentei sugerir. Mas não tem sido objeto de um tratamento mais direto e sistemático.

A ausência dessa reflexão talvez se explique pela força do cânone modernista na academia brasileira, mas, paradoxalmente, ela faz preponderar o pós-modernismo na análise da cultura, independentemente de uma inclinação teórica pós-moderna nos respectivos campos e subcampos acadêmicos, uma vez que a desconfiança pós-moderna da ideia de totalidade reverbera no estilhaçamento da cultura como objeto. É difícil dar conta das conexões estruturais entre as diferentes formas de produção cultural a partir de campos tão segmentados e que, pela especialização hoje requerida ao pesquisador brasileiro, acabam tendo pouco diálogo entre si. Qual o lugar institucional desse debate?

Longe de uma democracia cultural ampla, em que múltiplos critérios de legitimidade convivem sem se contrapor, estamos em um contexto no qual as disputas pela consagração cultural persistem entre agentes com posições muito desiguais e para as quais a proximidade ou distância em relação ao modernismo ainda é decisiva. Mas a dinâmica do campo cultural brasileiro mudou com a consolidação de uma indústria cultural, cujo poder de socialização sobre os próprios artistas e intelectuais é fato. Mesmo que não vejam TV, mesmo que não escutem música pop, mesmo que nunca tenham assistido a um filme de Spilberg. Ela é pervasiva e traça o contexto no qual nos movemos todos. 
Abstract: This paper discusses the possible causes and consequences of the low status of the media as an object in the academic field of sociology. It analyzes recent trends in the Brazilian cultural field that indicate the decline of the modernist canon, caused by the emergence of generations of artists, intellectuals and public under decisive influence of the cultural industry.

Keywords: Sociology of Communications, Sociology of Culture, Modernism, postmodernism, cultural industry

\section{Referências Bibliográficas}

ARRUDA, Maria Arminda do Nascimento. A Embalagem do Sistema - A Publicidade no Capitalismo Brasileiro. São Paulo: Duas Cidades, 1985.

. "Pensamento brasileiro e sociologia da cultura: questões de interpretação". Tempo Social, v.16 n.1 São Paulo jun, 2004.

. "Sociologia da Cultura e Sociologia da Comunicação de Massa: Esboço de uma Problemática". In: C. B. Martins; H. H. T. de S. Martins (orgs.) Horizontes das Ciências Sociais no Brasil: Sociologia. São Paulo: Editora Barcarolla Ltda, 2010, p. 253-277.

BARBERO, Jesus Martin. Dos Meios às Mediações - comunicação, cultura e hegemonia. Rio de Janeiro: Editora da UFRJ, parte II, 2001.

BOURDIEU, Pierre. "O mercado dos bens simbólicos". In: S. Miceli (org.). A economia das trocas simbólicas. São Paulo: Perspectiva, 1982.

CALDAS, Waldenyr. Acorde na Aurora. Dissertação de Mestrado em Ciência Social. São Paulo: Universidade de São Paulo, 1976.

CARVALHO, José Jorge. O Lugar da Cultura Tradicional na Sociedade Moderna. Brasília: UNB, Série Antropologia, número 77, 1989.

COHN, Gabriel. Sociologia da Comunicação - Teoria e Ideologia. São Paulo: Pioneira, 1973.

Nova, $\mathrm{n}^{\circ} 43,1998$.

. "A atualidade do conceito de indústria cultural". In: A. S. Moreira

(org.) Sociedade Global: Cultura e Religião. Petrópolis: Vozes, 1998. 
. Crítica e Resignação - Fundamentos da Sociologia de Max Weber.

São Paulo: T. A. Queiroz, 1979.

. "Concepção Oficial de Cultura e Processo Cultural". Revista do Patrimônio Histórico e Artísitico Nacional, Rio de Janeiro, 1987, p. 7-10. COHN, Gabriel. "A Concepção Oficial de Cultura nos Anos 70". Estado e Cultura no Brasil, São Paulo: Difel, 1984, p. 85-96.

. "Fine differences: from Simmel do Luhmann". Brazilian Review Of Social Sciences, 2003, p. 11-120.

. Perfis em teoria social: Tocqueville Weber, duas vocações. São Paulo: Lua Nova, 2000.

. "Difícil reconciliação: Adorno e dialética de cultura". Lua Nova, São Paulo, n. 20, 1990, p. 5-18.

FADUL, Anamaria. "Pesquisa e ensino nos 25 anos da Intercom". In: C. Peruzzo; R. Silva (orgs.) Retrato do ensino em comunicação no Brasil. São Paulo: Intercom; Taubaté: Unitau, 2003, p. 264.

JAMESON, Fredric. Pós-modernismo: a lógica cultural do capitalismo tardio. São Paulo: Ática, 1996

ORTIZ, Renato. A moderna tradição brasileira. São Paulo: Brasiliense, 1988.

lo. Maio, 2002.

. "As ciências sociais e a cultura". Tempo Social. vol.14 n. 1 São Pau-

LIMA, Luiz Costa. Teoria da cultura de massa. 2a. ed. (1a ed. 1970) São Paulo: Paz e Terra, 1978

MARCONDES FILHO, Ciro. Elementos para uma estética sociológica. Dissertação de Mestrado em Ciência Social. São Paulo: Universidade de São Paulo, 1976. no 16, dez, 2001. . "Haverá vida após a internet?". Revista FAMECOS. Porto Alegre, MICELI, Sérgio. A Noite da Madrinha. São Paulo: Perspectiva, 1982.

. "Entre no ar em Belíndia---- A Indústria Cultural Hoje". Cadernos IFCH. Campinas: UNICAMP, outubro, 1984. 

. Intelectuais e classe dirigente no Brasil (1920-1945). São Paulo, Di-

fel, 1979.

MIRANDA, Orlando Pinto. Tio Patinhas e os Mitos da Comunicação. Dissertação de Mestrado em Ciência Social. São Paulo: Universidade de São Paulo, 1975.

MINISTÉRIO DA CULTURA. Plano Nacional de Cultura, 2009. Disponível no site do Minc em junho de 2011.

RIDENTI, Marcelo. "Artistas e Intelectuais no Brasil pós 1960". Tempo social, vol. 17, n 1, SP: USP, Departamento de Sociologia, 2005.

ROCHA, Maria Eduarda da Mota. "Guel Arraes: Leitura Social de uma Biografia". In: Y. Fechine; A. Figueroa (editores) Guel Arraes: um inventor no audiovisual brasileiro. Recife: CEPE, 2008.

. O Consumo Precário: Pobreza e Cultura de Consumo em São Miguel dos Milagres. Maceió: Edufal, 2002.

RUDIGER, Francisco. "Comunicação e Indústria Cultural: a fortuna da teoria crítica nos estudos de mídia brasileiros". Revista Brasileira de Ciências da comunicação. Intercom: São Paulo, vol. XXI, n. 2, jul./dez, 1998, p. 13-25.

TASCHNER, Gisela. Do Jornalismo Político à Indústria Cultural. Mestrado em Ciência Social. São Paulo: Universidade de São Paulo, 1978.

WILLIAMS, Raymond. Cultura: Sociologia da Comunicação e da arte. Rio de Janeiro: Paz e Terra, 1992. 